\title{
Enhancement of Integrated Solar Collector with Spherical Capsules PCM Affected by Additive Aluminum Powder
}

\author{
Fatah O. Al Ghuol, K. Sopian, and Shahrir Abdullah \\ Solar Energy Research Institute, Faculty of Engineering, Universiti Kebangsaan Malaysia UKM, 43600 Bangi, Selangor, Malaysia \\ Correspondence should be addressed to Fatah O. Al Ghuol; fatah_alghuol@yahoo.com
}

Received 18 September 2015; Revised 24 December 2015; Accepted 27 December 2015

Academic Editor: Angelo Lucia

Copyright ( 2016 Fatah O. Al Ghuol et al. This is an open access article distributed under the Creative Commons Attribution License, which permits unrestricted use, distribution, and reproduction in any medium, provided the original work is properly cited.

\begin{abstract}
This research aims to study, analyze, design, and construct a solar air heater combined with an appropriate phase-change material (PCM) unit. This solar air heater is analogous to a collector integrating a thermal storage unit and a solar thermal collector. In this study, such single-pass solar air heater in amalgamation with PCM was constructed, and several tests were conducted on this device. During the experiments for the solar collector with PCM (spherical capsules), the temperature varied between $30^{\circ} \mathrm{C}$ and $35^{\circ} \mathrm{C}$, and the air mass flow rate ranged between 0.03 and $0.09 \mathrm{~kg} / \mathrm{s}$. Results confirmed the predicted experimental findings. With the use of paraffin wax-aluminum composite, the thermal storage efficiency of the constructed solar air heater reached a maximum value of $71 \%$ at $0.05 \mathrm{~kg} / \mathrm{s}$ mass flow rate, its charging time decreased by almost $70 \%$, and its cooling rate increased. The thermal storage efficiency of the compound composite was $76.8 \%$ at $0.07 \mathrm{~kg} / \mathrm{s}$ mass flow rate. The results also indicated that the time of charging decreased by almost $60 \%$ with the use of paraffin wax-aluminum composite.
\end{abstract}

\section{Introduction}

In recent years, the cost of fossil fuels has considerably increased because people are shifting to alternative fuels. Among the alternatives, solar energy is becoming a quite popular and reliable source of heat energy because of its unlimited supply. Substantial work is undertaken to harness solar energy for heating needs in an economical way. However, the irregular availability of sunlight is a serious issue in the development of solar technology. To address this problem, a heat energy storage system using both latent and sensible heat needs to be developed [1]. Thermal energy storage systems are at the center of focus because of their isothermal behavior during the discharging and charging processes and their high thermal energy storage capacity per unit volume [2].

Investigation of the melting characteristics of a heat storage circular capsule inserted with phase-change material(PCM-) saturated porous metal indicated that the effect of thermal conductivity on melting time can be observed. The thermal performance of a solar latent heat storage unit was analyzed using numerical analysis by El Qarnia [3]. For this analysis, several PCMs were used for water heating; moreover, considering the climatic conditions in Marrakech City during summer, the number of tubes, PCM mass, and water flow rate were adjusted [3].

Aluminum is commonly used by researchers in their experimental studies. Ho and Gao [4] recently examined the thermophysical characteristics of PCM, including density, dynamic viscosity, thermal conductivity, and latent heat of fusion; their results indicated that the dynamic viscosity of paraffin was enhanced by adding aluminum particles. Xiao and Zhang [5] found that the addition of aluminum particles effectively decreased the charging and discharging times on the solidification and melting of paraffin present in a solar collector. The results also indicated that the efficiency of the PCM composite was better than that of pure paraffin [5]. Preinstalled PCM storage units are not commonly used in solar air heaters because the conductivity of PCM is very difficult to enhance [6]. An air heater with a sensible storage medium situated beneath the absorber plate was used for crop drying by Jain and Tewari [7]. Air was allowed to flow in between the two types of glazing present in the collector and then passed into the crop dryer through the bottom of 


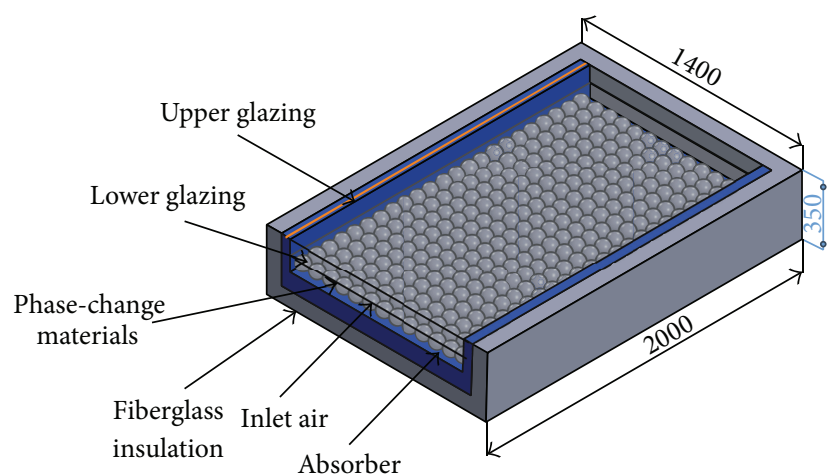

FIGURE 1: Schematic drawing of collector with PCM storage.

the combined absorber-storage unit; during the experiment, $900 \mathrm{~W} / \mathrm{m}^{2}$ radiations were generated, and only a temperature increase of $5^{\circ} \mathrm{C}$ was observed overnight [7].

The present study mainly aims to construct a single-pass solar air collector with a PCM unit and intensively examine every detail of the design. The work is conducted along with the assessment of the viability of the production of simple solar distillers in the Mechanical Engineering Laboratory of the AL Zawiya University. The influence of aluminum mass fraction on the parameters is also studied and analyzed.

\section{Design and Fabrication of PCM Capsules with Solar Collector}

PCM should be placed in such a way that heat can directly and easily transfer from the absorber to the storage medium and then easily transfer to the air in the absence of the sun. Thus, in the proposed design, the PCM was only beneath and in direct contact with the absorber plate (Figure 1). A builtin PCM unit provides many benefits: a secondary working fluid loop is no longer required, additional control systems and instruments for storing heat are not needed, a low-heatcapacity working fluid is not needed for the transfer of heat, and the cost and intricacy involved in the design are reduced. Moreover, a lower amount of material is needed for storing the same heat quantity because the sensible heat of the PCM, like paraffin wax, is 100 times less than its latent heat, which is also the case for other solids. The output temperature of the collector is stabilized with the use of PCM as the storage medium because the PCM stores the heat near the melting temperature [8]. High thermal conductivity in the storage material is also no longer required because of the small volume [9].

\section{Experimental Investigation}

The designed PCMs were cylindrical in shape to support the symmetrical expansion of paraffin wax in all directions and ensure that no leakage occurs in the container. The PCM unit comprised several PVC spherical capsules that are $7.5 \mathrm{~cm}$ in diameter, which served as both thermal energy storage and solar energy absorber. Notably, the author in the Mechanical
TABLE 1: Capsules physical dimensions.

\begin{tabular}{lc}
\hline Parameters & Value \\
\hline Number of capsules & 70 \\
Capsule diameter & $2.5 \mathrm{~cm}$ \\
Total weight of PCM & $53 \mathrm{~kg}$ \\
\hline
\end{tabular}

TABLe 2: Physical dimensions of the tested thermal air collector.

\begin{tabular}{lc}
\hline $\begin{array}{l}\text { Solar collector } \\
\text { parameter }\end{array}$ & Value \\
\hline Width & $128 \mathrm{~cm}$ \\
Length & $300 \mathrm{~cm}$ \\
Depth & $10 \mathrm{~cm}$ \\
Height & $15 \mathrm{~cm}$ \\
Spacing between each row's & $0.2-0.4 \mathrm{~cm}$ \\
capsules & $217 * 120 \mathrm{~cm}$ \\
Effective glazing area & $0.4 \mathrm{~cm}$ \\
\hline
\end{tabular}

TABLE 3: Thermophysical properties of the paraffin wax phasechange material.

\begin{tabular}{lc}
\hline Property & Value \\
\hline Latent heat of fusion & $189 \mathrm{~kJ} / \mathrm{kg}$ \\
Melting temperature & $53-54^{\circ} \mathrm{C}$ \\
Thermal conductivity & $0.2 \mathrm{~W} / \mathrm{m} \cdot \mathrm{K}$ \\
Specific heat & $2.5 \mathrm{~kJ} / \mathrm{kg} \cdot \mathrm{K}$ \\
Liquid density & $770 \mathrm{~kg} / \mathrm{m}^{3}$ \\
Kinematic viscosity & $3.3-3.6 \mathrm{~mm}^{2} / \mathrm{s}$ at $373 \mathrm{~K}$ \\
\hline
\end{tabular}

Engineering Laboratory of the AL Zawiya University was able to construct 70 capsules manually.

The PCM unit comprised ten rows of seven spherical capsules. The spherical capsule PCM unit was $0.15 \mathrm{~cm}$ in thickness and $7.5 \mathrm{~cm}$ in diameter, and the length and width of the collector were 2.450 and $1.32 \mathrm{~m}$, respectively. The aluminum used was in particle form with a particle size of $70 \mu \mathrm{m}$. To store the thermal energy and absorb the radiation arrays of PCM capsules, top-glazed isolated duct and air pump were used. The system was designed in a way that heat can be discharged for use in the absence of the sun.

The physical dimensions of the capsule are summarized in Table 1. For efficiency and convenience, a hole was drilled into one end of the spherical capsule; thus, additional material can be inserted if the heat transferred should be augmented. During the charging process, the screws were closed as the paraffin wax was in liquid phase; hence, the PCM pressure can be decreased. This design also allowed the spherical capsules to be used multiple times. Another feature for increasing the efficiency of the system was to paint the outer surface of each spherical capsule black for better heat absorption. An electrothermal melting point apparatus was used to determine the melting point of PCM. Tables 2 and 3 present the dimensions and thermophysical properties of the tested thermal air collector, respectively. 


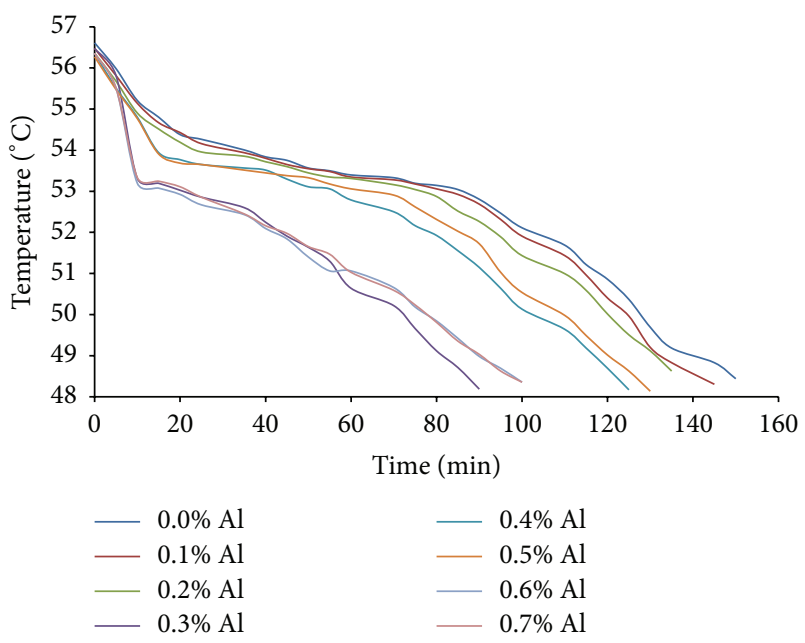

FIgURE 2: PCM temperature variations versus the time during the solidification process for PCM at various aluminum mass fractions $\left(m=0.03 \mathrm{~kg} / \mathrm{s}\right.$ and $\left.T_{1}=30^{\circ} \mathrm{C}\right)$.

The air is very soluble in liquid state while it is insoluble in solid paraffin wax due to which on freezing the paraffin volume decreased by $10 \%$; this change in volume is unnoticed. Subsequently, the change of volume results in decreased heat transfer. Pielichowska and Pielichowski [10] indicated that the properties of wax can be changed by dissolved air. To address this serious issue, two strategies may be employed. One is to remove some of the liquid before freezing the paraffin mixture, and the other is to choose a suitable container shape. Before placing the nylon cap and closing the spherical capsules, the liquid paraffin wax was filled in the spherical capsules, and, then by simply tapping the spherical capsules, air bubbles were removed. The spherical capsules were subsequently closed. Afterward, the pressure inside the capsule dropped below the atmospheric pressure, and the wax converted from liquid to solid state. By making three spherical units in the middle, right, and left and then inserting nine thermocouples, the PCM temperature can be easily observed and analyzed. This setup was applied to only one of the spherical capsules [11]. Moreover, the same epoxy was used to prevent the leaking problem. To increase the thermal conductivity of the additional materials, those with high thermal conductivity can be inserted into the spherical. The complete procedure was conducted with extreme care to avoid any leakage.

As previously mentioned, the aluminum used is in particle form and very small at approximately $<100 \mu \mathrm{m}$. A tiny aluminum particle size was adopted to avoid adverse behavior of the particles, like settling down in the spherical capsules or floating above the melted paraffin, which can ultimately influence the heat transfer process. Homogeneous amalgamation of aluminum with the mixture is only possible if the aluminum size is small $(70 \mathrm{~g})$.

\section{Results and Discussion}

The results obtained through the experiments have been mentioned in the study. The results include the observation

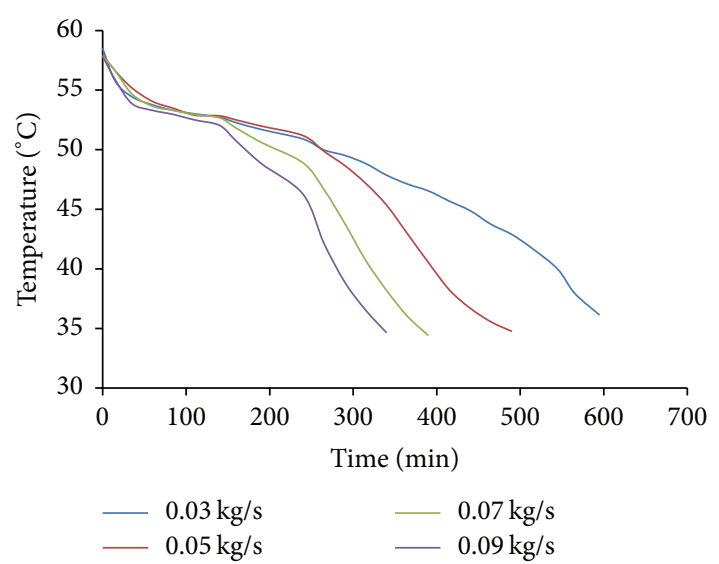

(a)

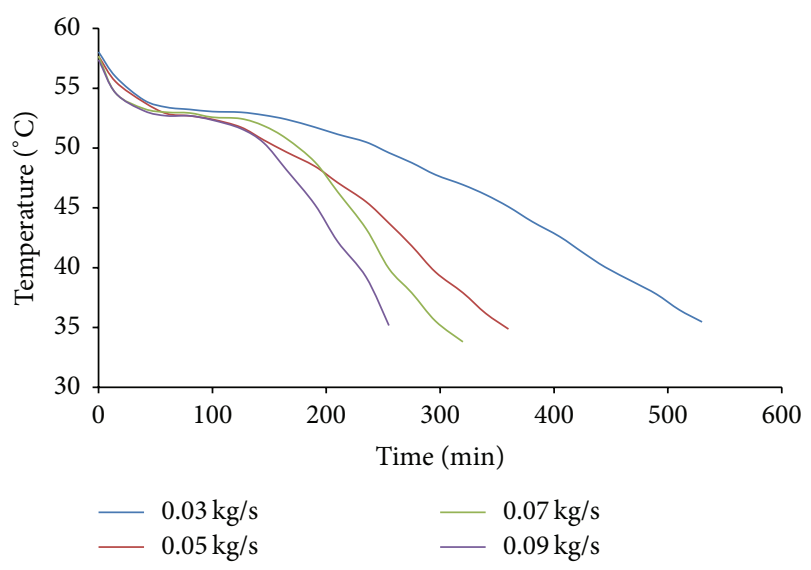

(b)

Figure 3: PCM temperature variations versus the time during the solidification process for the pure paraffin wax at various mass flow rates and (a) $T_{1}=30^{\circ} \mathrm{C}$ and (b) $T_{1}=35^{\circ} \mathrm{C}$.

of the instantaneous temperature of the collector, freezing time, and the air temperature at the outlet during discharging of heat. The effect of the operation of the unit on several other parameters likes inlet temperature; mass flow rate and additive mass fraction have also been deliberated.

4.1. Effect of Aluminum Powder Ratio on Solidification Time. An increase from $0.1 \%$ to $0.7 \%$ in the mass fraction additive ratio was observed which supported the adjustment of the mass fraction to make it suitable for use on compound. The cooling rate was found to increase for $0.6 \%$ mass fraction while solidification time decreased and the PCM was observed to work efficiently as a sensible storage material which would ultimately affect the air temperature at the outlet. This can also be seen from Figure 2 where the cooling rate will increase enhancing the discharge time with increase in mass fraction. Mostly in our experiments $0.5 \%$ mass fraction has been used and suitable results have been obtained.

The change in the PCM temperature with the solidification process time for compound and pure paraffin wax can be observed from Figure 3 which depicts the graph of PCM temperature versus the solidification process time for several 


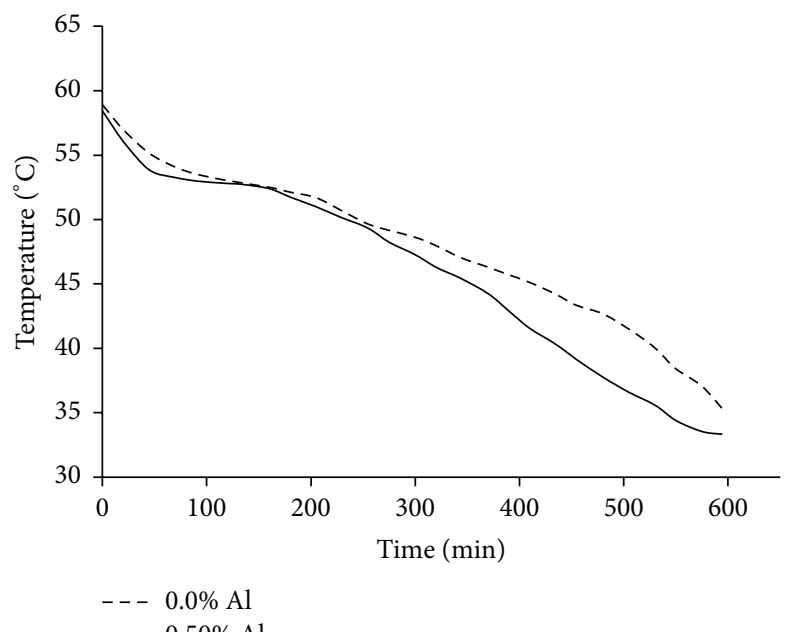

(a)

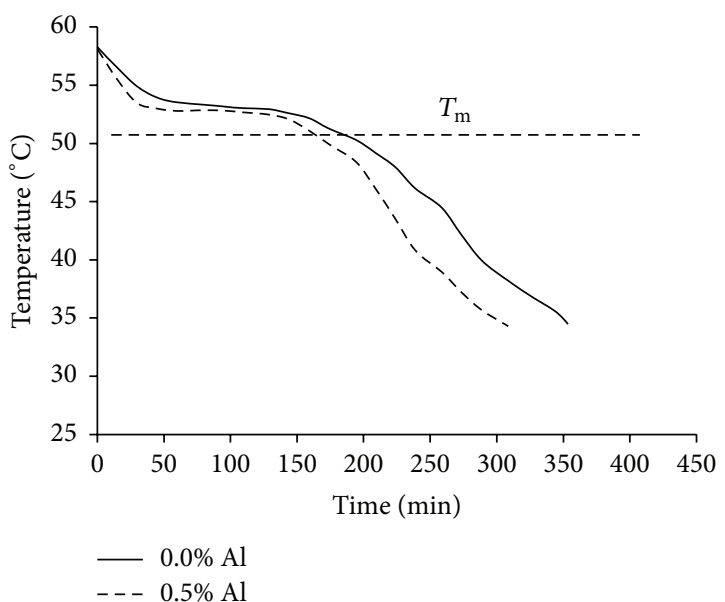

(c)

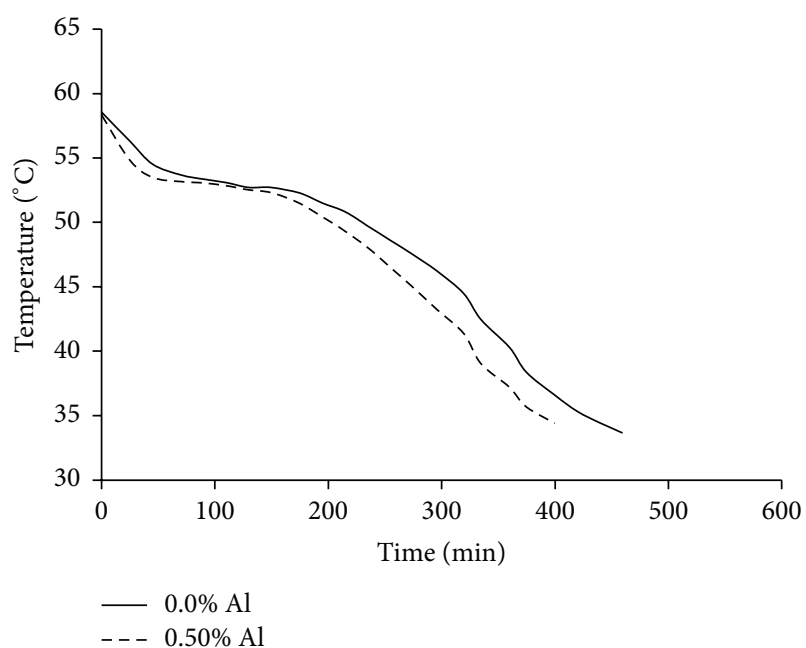

(b)

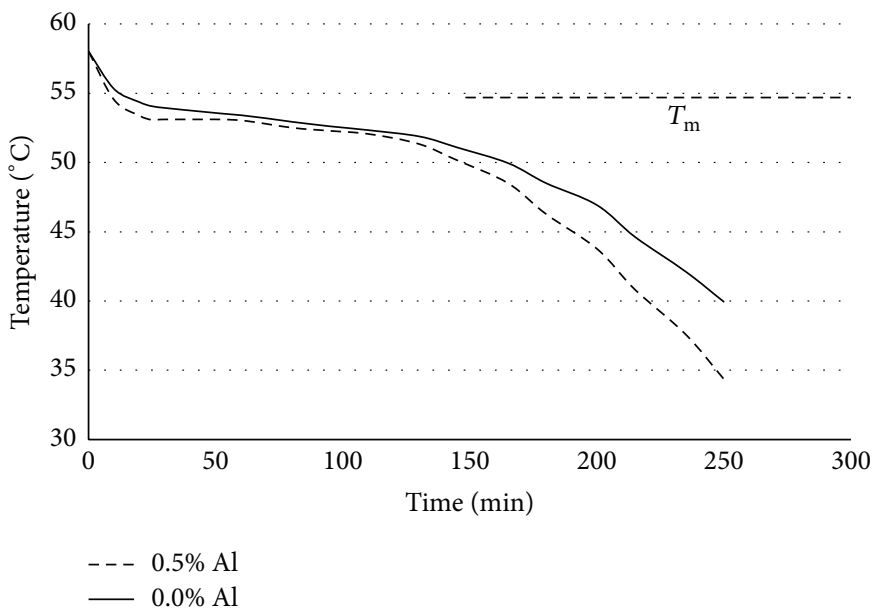

(d)

Figure 4: PCM temperature variations versus the time during the solidification process.

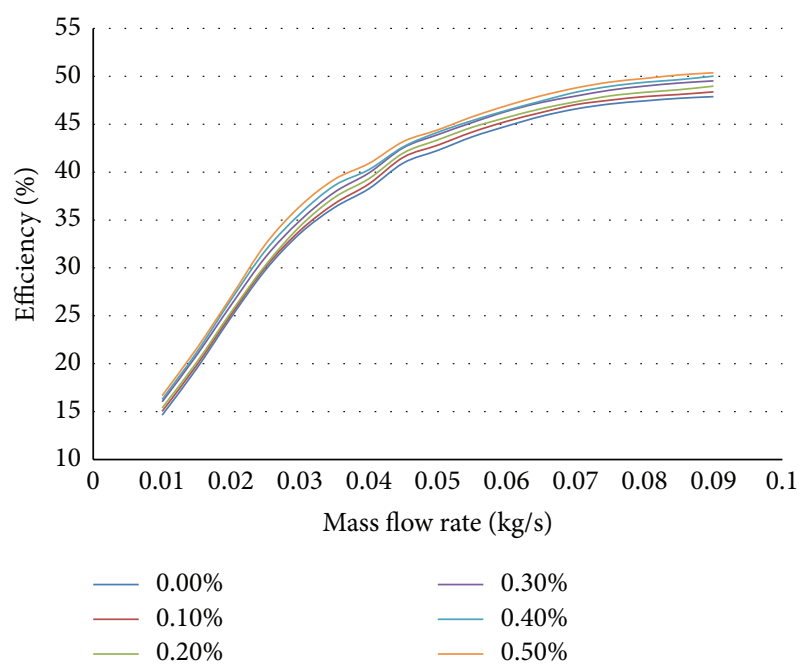

FIGURE 5: Effect of the mass flow rate on the thermal storage efficiency for the pure paraffin wax with different aluminum ratios when $T_{\text {in }}=35^{\circ} \mathrm{C}$.

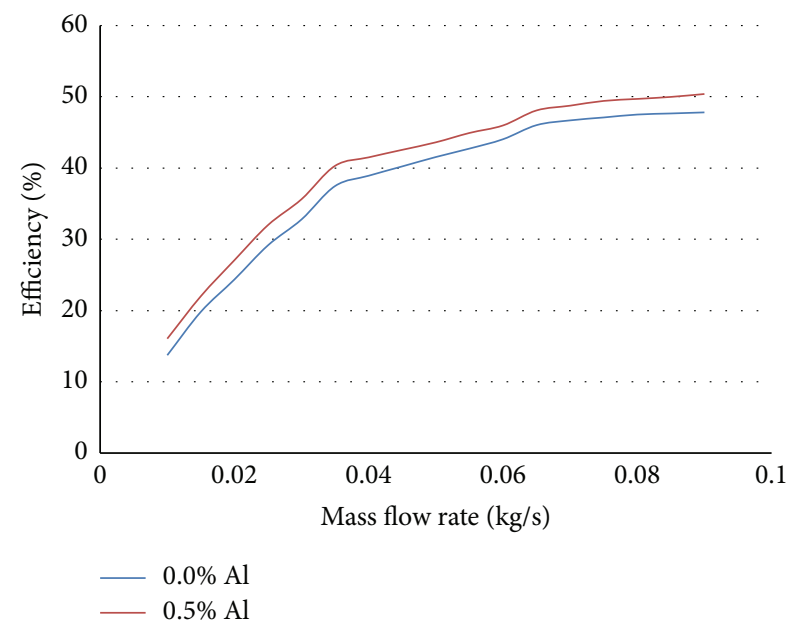

FIGURE 6: Effect of the mass flow rate on the thermal storage efficiency for the pure paraffin wax and with the compound when $T_{\text {in }}=35^{\circ} \mathrm{C}$. 


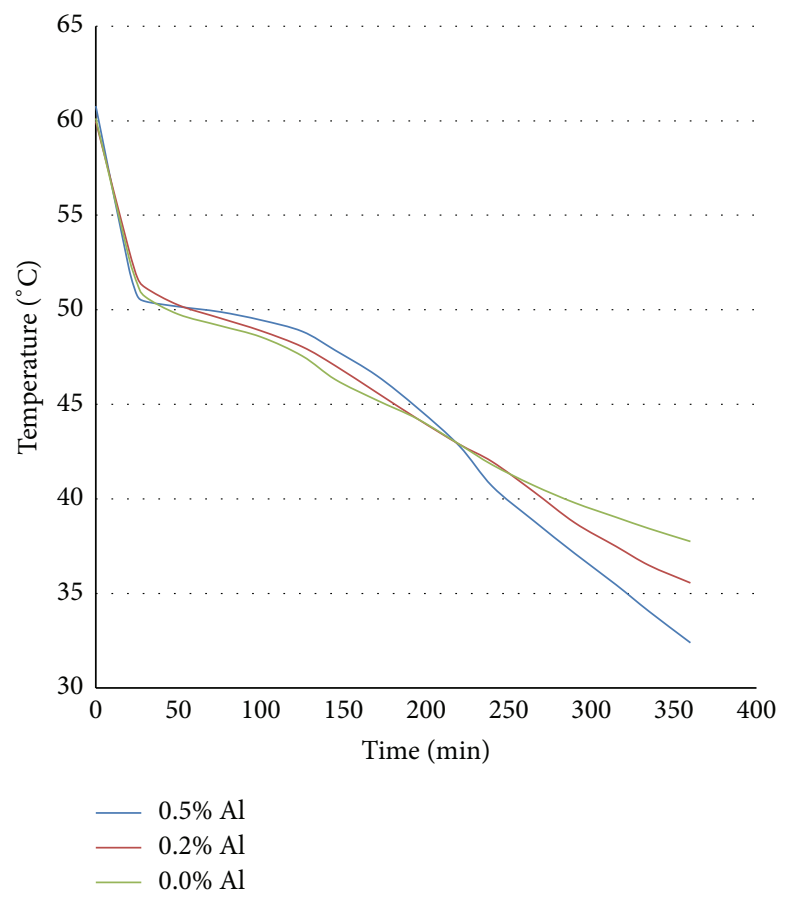

(a)

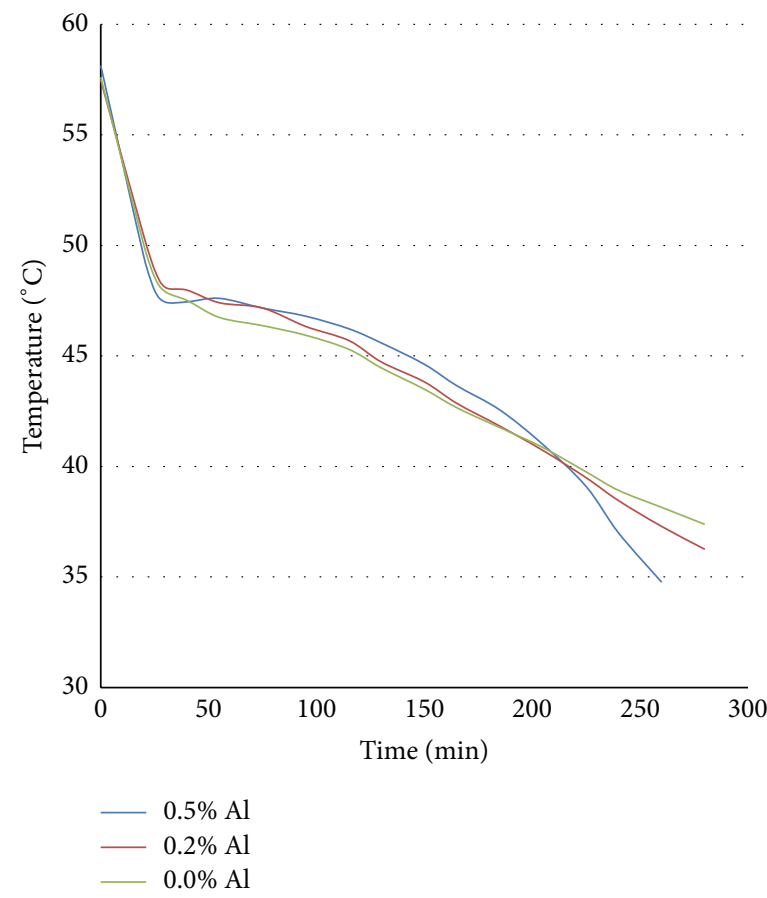

(c)

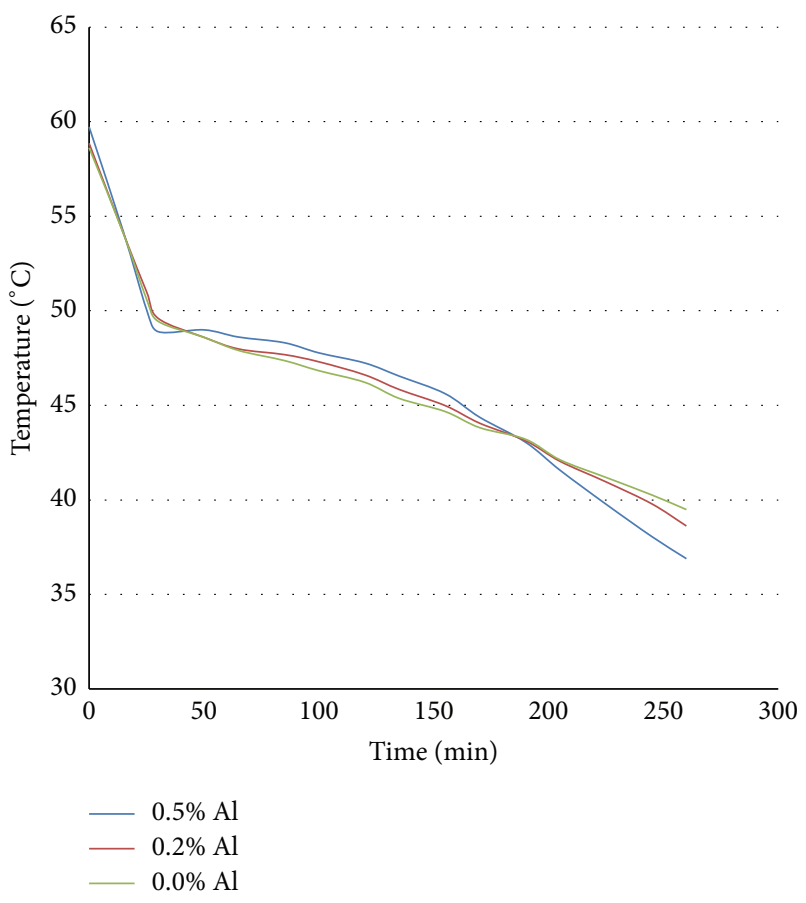

(b)

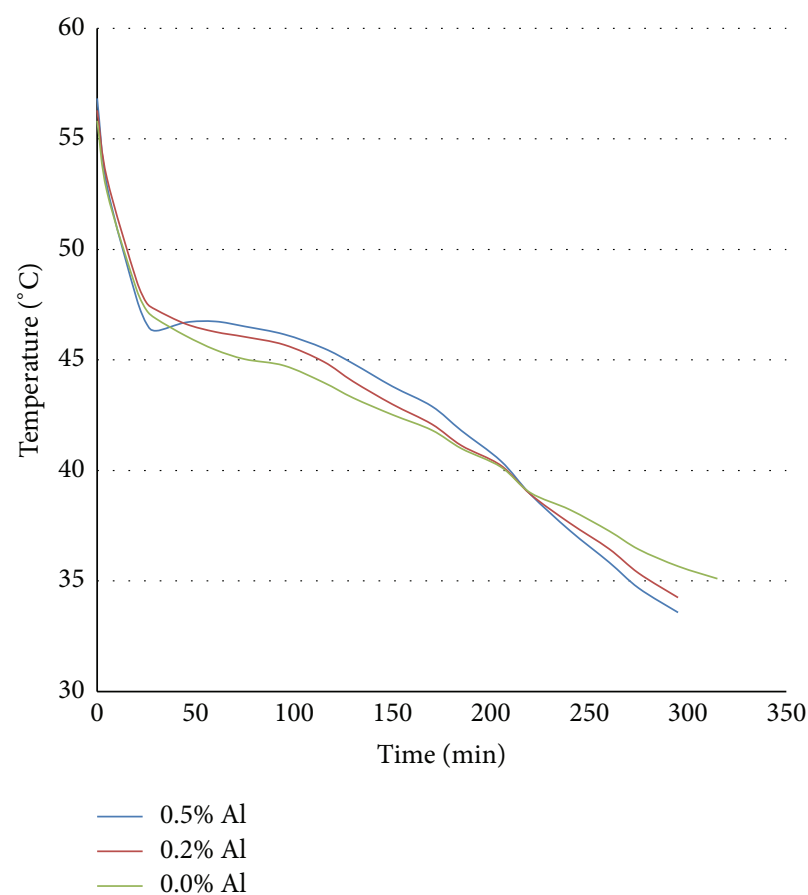

(d)

FIGURE 7: The effect of the aluminum mass fraction on the outlet temperature at the mass flow rate of $T_{\text {in }}=30^{\circ} \mathrm{C}$ and mass flow rate of (a) $0.03 \mathrm{~kg} / \mathrm{s}$, (b) $0.05 \mathrm{~kg} / \mathrm{s}$, (c) $0.07 \mathrm{~kg} / \mathrm{s}$, and (d) $0.09 \mathrm{~kg} / \mathrm{s}$.

different mass flow rates and $T_{1}\left(30^{\circ} \mathrm{C}\right.$ and $\left.35^{\circ} \mathrm{C}\right)$. Several deductions have been made by studying and analysing the graph. In the initial phase of the experiment the air is at the same temperature as the outlet PCM temperature. But soon the temperature decreased rapidly to $57^{\circ} \mathrm{C}$. At the end of the discharging process the outlet air temperature reduces to $53^{\circ} \mathrm{C}$; this temperature makes sure that the PCM freezes in the tank. During the interval the temperature remains constant. The discharging time depends on the mass flow rate as shown in Figure 3(a) and it was observed that for $0.09 \mathrm{~kg} / \mathrm{s}$ the discharge time was $260 \mathrm{~min}$, for mass flow rate of $0.07 \mathrm{~kg} / \mathrm{s}$ the time was $310 \mathrm{~min}$, and for $0.05 \mathrm{~kg} / \mathrm{s}$ the time was $370 \mathrm{~min}$ 


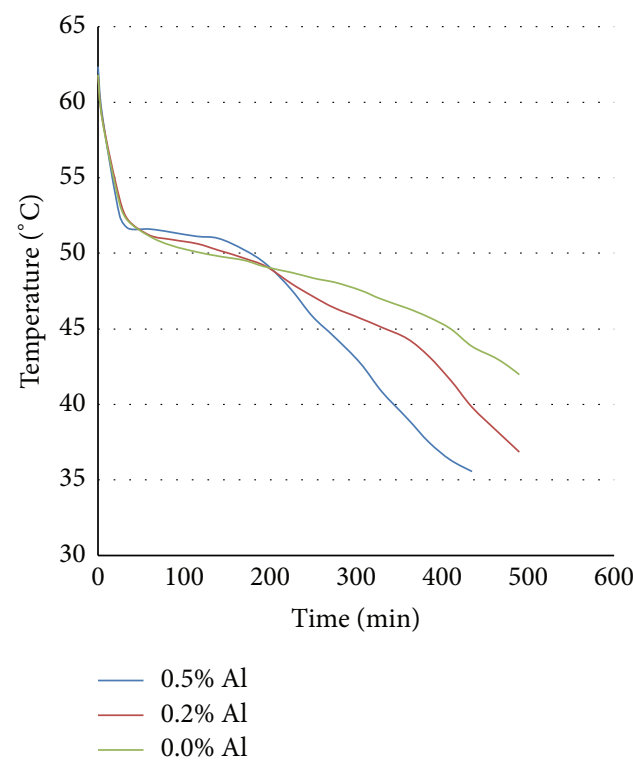

(a)

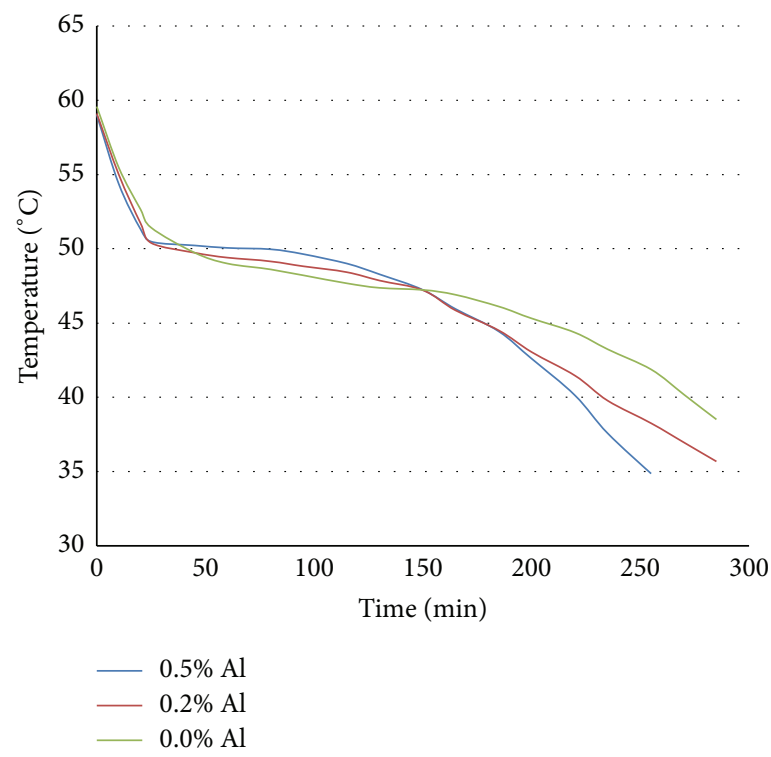

(c)

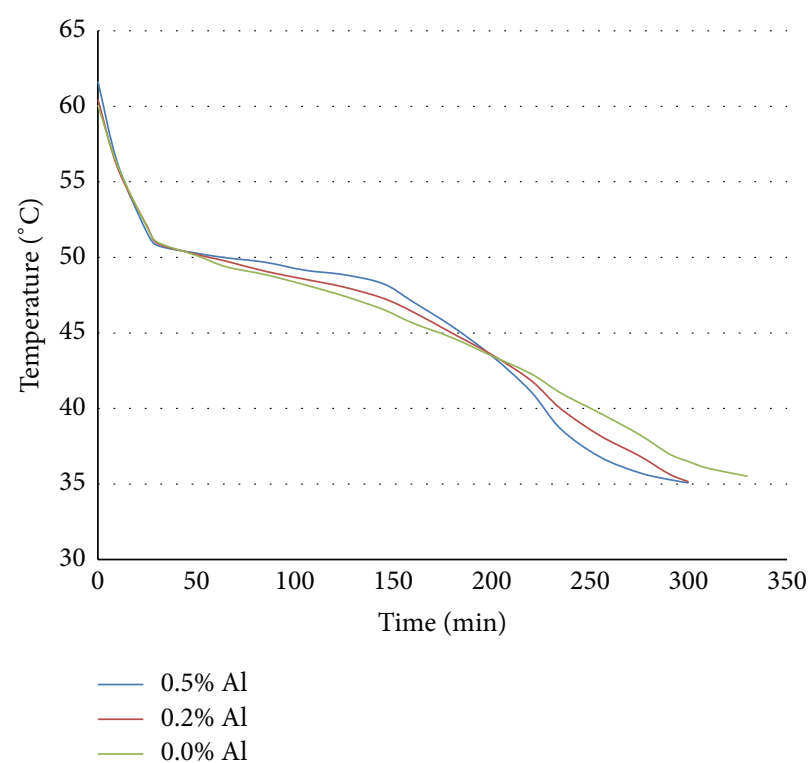

(b)

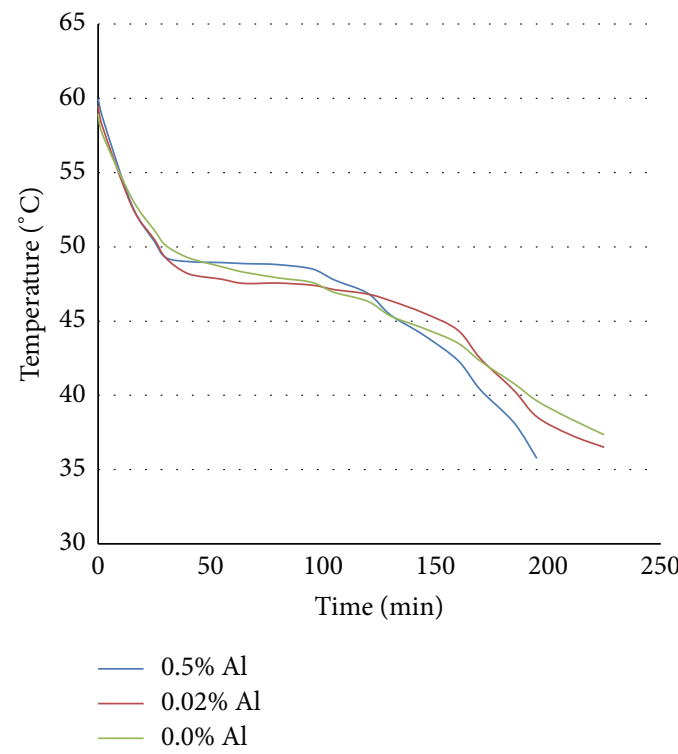

(d)

Figure 8: The effect of the aluminum mass fraction on outlet temperature at mass flow rate of $T_{\text {in }}=35^{\circ} \mathrm{C}$ and mass flow rate of (a) $0.03 \mathrm{~kg} / \mathrm{s}$, (b) $0.05 \mathrm{~kg} / \mathrm{s}$, (c) $0.07 \mathrm{~kg} / \mathrm{s}$, and (d) $0.09 \mathrm{~kg} / \mathrm{s}$.

while for $0.03 \mathrm{~kg} / \mathrm{s}$ mass flow rate the time was found to be $530 \mathrm{~min}$. Figure 4 illustrates the solidification temperatures of the PCM with varying mass flow rates. A graph of the PCM temperature versus the solidification process time for composite and paraffin wax has been shown in Figure 4(a) having $T=35^{\circ} \mathrm{C}$ and $0.03 \mathrm{~kg} / \mathrm{s}$ mass flow rate. On addition of $0.50 \%$ aluminum powder the solidification time enhanced but a reduction in the discharge time was observed.

On comparing the solidification time and the thermal response duration for both pure wax and composite for varying mass flow rates an improvement was observed in the time durations. The enhancement and constancy of the melting point have been shown in Figures 4(c) and 4(d).
On the other hand, the discharge time decreased for the compound by 5 minutes.

\subsection{Thermal Storage Performance of Solar Air Heater with} PCM Unit. In this portion of the study, the determination of the thermal storage efficacy regarding the additive ratio in proportion to thermal storage medium has been studied. Figures 5 and 6 depict the thermal storage performance for different mass flow rates and aluminum ratios. The aluminum particle used was $701 \mathrm{~m}$ in size. Figure 5 illustrates the different tested mass fractions of the PCM-aluminum compound. No major change in the efficiency could be observed for a change of mass flow rate from $0.05 \mathrm{~kg} / \mathrm{s}$ to $0.09 \mathrm{~kg} / \mathrm{s}$; when 
the mass flow rate was $0.05 \mathrm{~kg} / \mathrm{s}$ the thermal storage efficiency for pure paraffin wax and compound was maximum having a value of $71 \%$ while in the case of $0.07 \mathrm{~kg} / \mathrm{s}$ the efficiency was found as $76.8 \%$. However, an increase of efficiency from $21.7 \%$ to $78.9 \%$ was observed in the overall experiment. The increase in the aluminum ratios in the paraffin wax improved the thermal conductivity of PCM and hence the thermal storage efficiency as shown in Figure 6.

4.3. Effect of Aluminum Mass Fraction on Outlet Air Temperature. The addition of the aluminum particles in the PCM improves the thermal conductivity of the material and hence improves the heat transfer ability of the material and better heat exchange between fluid and PCM.

Figures 7 and 8 show the effect of the aluminum mass fraction on the outlet air temperature $T_{1}=30^{\circ} \mathrm{C}$ and $T_{1}=$ $35^{\circ} \mathrm{C}$, respectively, at difference values of mass flow rate. In the initial phase of the experiment during the state change period from approximately $t=25 \mathrm{~min}$ to $t=100 \mathrm{~min}$ the outlet temperature remained consistent and gave the greatest air temperature for $0.5 \%$ mass fraction of PCM having aluminum; this was observed for all mass flow rates and when the temperature at the inlets was $T_{1}=30^{\circ} \mathrm{C}$ and $T_{1}=35^{\circ} \mathrm{C}$. However, the discharge time for PCM having lower aluminum ratios was found to be long because lesser aluminum content resulted in poor heat transfer [12]. This can maintain the stable temperature for about 1 hour.

\section{Conclusions}

This study was conducted to develop a single product combining a solar thermal storage unit and a solar air heater. The experiment was performed in a solar simulator laboratory. In the course of this research, methods and techniques that can be used to augment and advance the thermal conductivity of the paraffin wax were developed and investigated. The spherical capsules were used to store thermal energy and tested as the absorber in the collector. Several tests were also conducted to increase the thermal conductivity and solar thermal storage ability of the PCM by adding aluminum; the thermal storage ability increased by $2.91 \%$. Experiments were also performed to increase the efficacy of a singleslope solar distiller with the use of paraffin on the base and sides. By enhancing the thermal efficiency, the discharging and charging times decreased, and an improvement in the solidification process time was observed.

\section{Conflict of Interests}

The authors declare that there is no conflict of interests regarding the publication of this paper.

\section{Acknowledgment}

The authors would like to thank Universiti Kebangsaan Malaysia for providing laboratory facilities and financial support.

\section{References}

[1] R. Jacob and F. Bruno, "Review on shell materials used in the encapsulation of phase change materials for high temperature thermal energy storage," Renewable \& Sustainable Energy Reviews, vol. 48, pp. 79-87, 2015.

[2] R. K. Sharma, P. Ganesan, V. V. Tyagi, H. S. C. Metselaar, and S. C. Sandaran, "Developments in organic solid-liquid phase change materials and their applications in thermal energy storage," Energy Conversion and Management, vol. 95, pp. 193228, 2015.

[3] H. El Qarnia, "Numerical analysis of a coupled solar collector latent heat storage unit using various phase change materials for heating the water," Energy Conversion and Management, vol. 50, no. 2, pp. 247-254, 2009.

[4] C. J. Ho and J. Y. Gao, "Preparation and thermophysical properties of nanoparticle-in-paraffin emulsion as phase change material," International Communications in Heat and Mass Transfer, vol. 36, no. 5, pp. 467-470, 2009.

[5] X. Xiao and P. Zhang, "Morphologies and thermal characterization of paraffin/carbon foam composite phase change material," Solar Energy Materials \& Solar Cells, vol. 117, pp. 451-461, 2013.

[6] N. Şahan, M. Fois, and H. Paksoy, "Improving thermal conductivity phase change materials-a study of paraffin nanomagnetite composites," Solar Energy Materials and Solar Cells, vol. 137, pp. 61-67, 2015.

[7] D. Jain and P. Tewari, "Performance of indirect through pass natural convective solar crop dryer with phase change thermal energy storage," Renewable Energy, vol. 80, pp. 244-250, 2015.

[8] S. A. Memon, H. Z. Cui, H. Zhang, and F. Xing, "Utilization of macro encapsulated phase change materials for the development of thermal energy storage and structural lightweight aggregate concrete," Applied Energy, vol. 139, pp. 43-55, 2015.

[9] E.-B. S. Mettawee and G. M. R. Assassa, "Thermal conductivity enhancement in a latent heat storage system," Solar Energy, vol. 81, no. 7, pp. 839-845, 2007.

[10] K. Pielichowska and K. Pielichowski, "Phase change materials for thermal energy storage," Progress in Materials Science, vol. 65, pp. 67-123, 2014.

[11] J. M. Khodadadi, L. Fan, and H. Babaei, "Thermal conductivity enhancement of nanostructure-based colloidal suspensions utilized as phase change materials for thermal energy storage: a review," Renewable and Sustainable Energy Reviews, vol. 24, pp. 418-444, 2013.

[12] S. F. Hosseinizadeh, A. A. Rabienataj Darzi, F. L. Tan, and J. M. Khodadadi, "Unconstrained melting inside a sphere," International Journal of Thermal Sciences, vol. 63, pp. 55-64, 2013. 

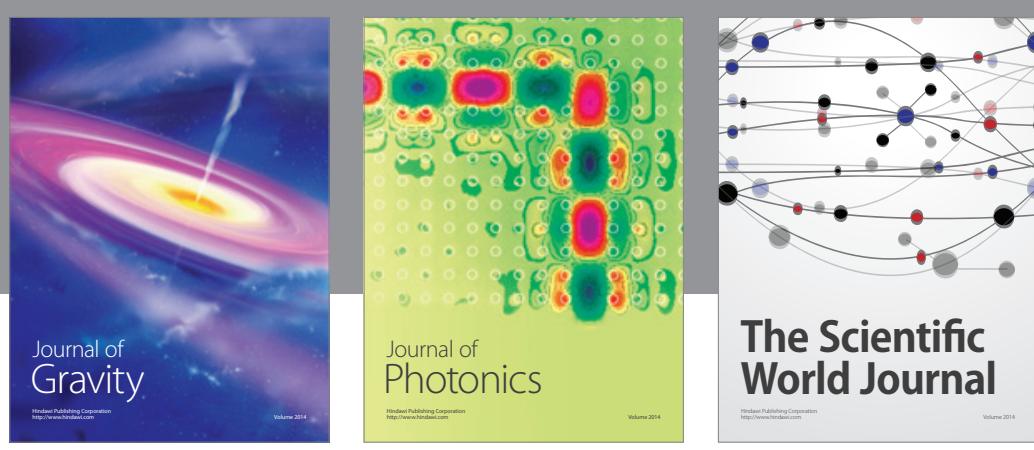

The Scientific World Journal
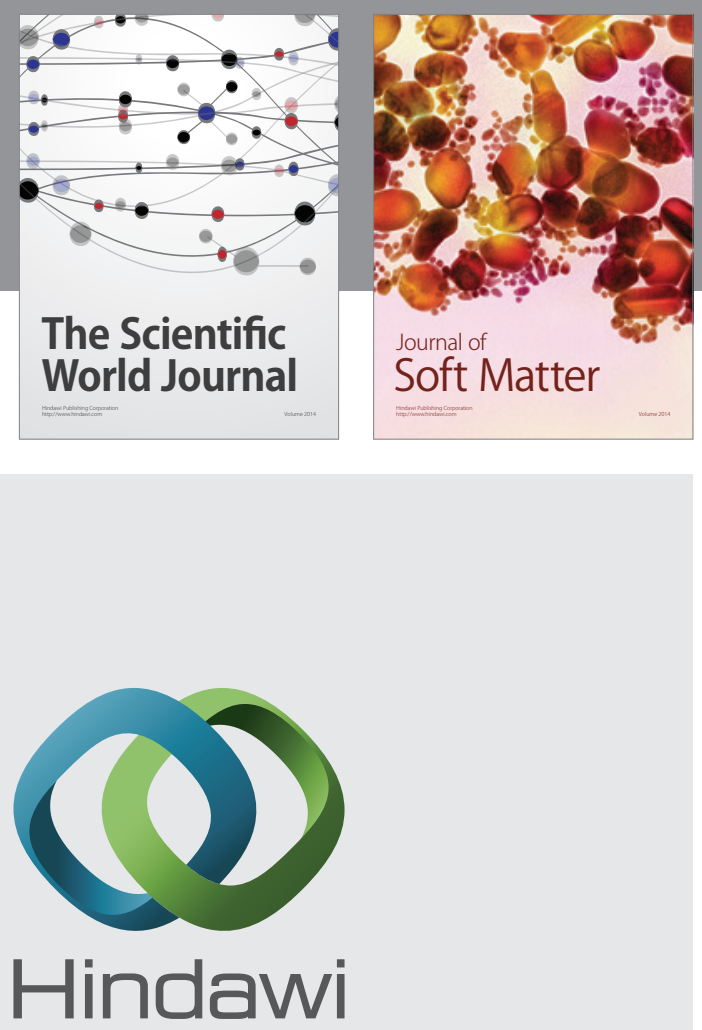

Submit your manuscripts at

http://www.hindawi.com

nternational Journal of

Statistical Mechanics
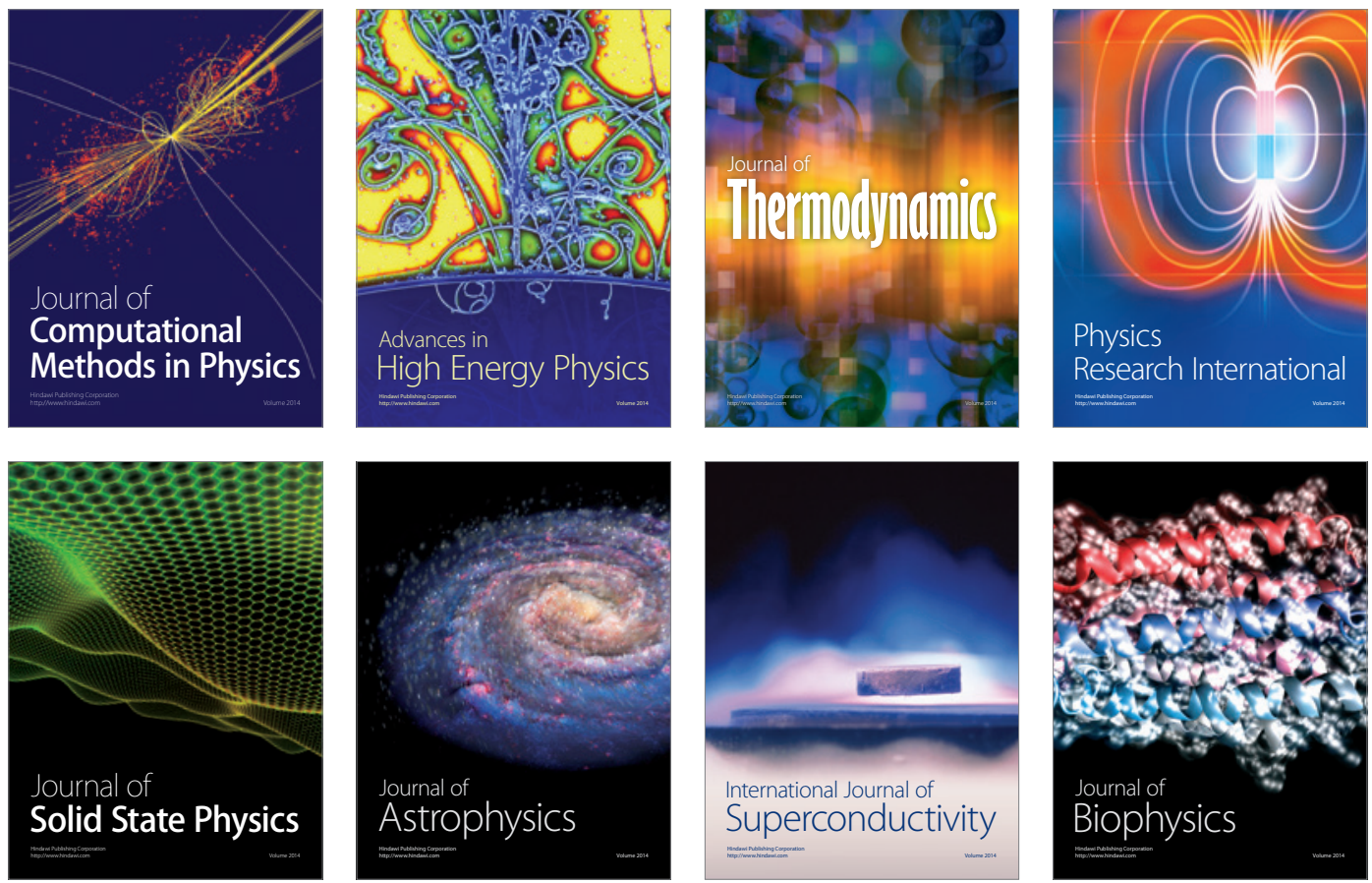
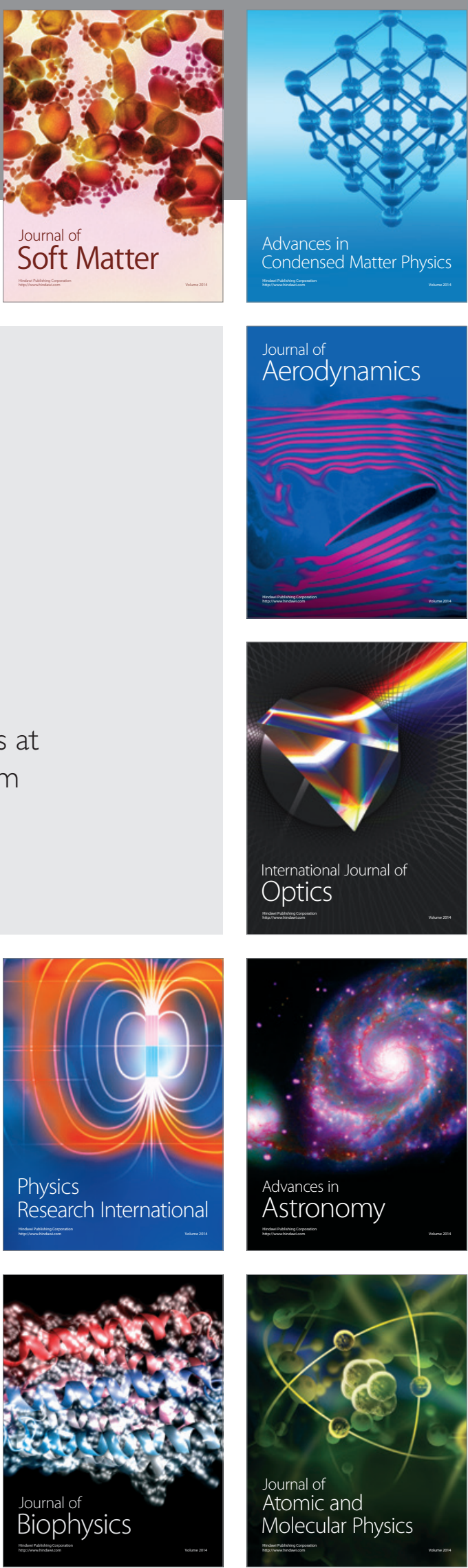